\title{
Preoperative Clinical Neurological Assessment in New-borns with Critical Congenital Heart Disease
}

\author{
Lozar Krivec J ${ }^{1}$, Kosmač $\mathrm{B}^{2}$, Paro-Panjan $\mathrm{D}^{1, *}$
}

\author{
${ }^{1}$ Division of Paediatrics, Department of \\ Neonatology, University Medical Centre \\ Ljubljana, Slovenia \\ ${ }^{2}$ Department of Paediatric Cardiology, \\ University Hospital RWTH Aachen, \\ Germany
}

\section{*Correspondence}

darja.paro@gmail.com (Paro-Panjan D)

\begin{abstract}
Objectives: To evaluate preoperative neurological abnormalities in term newborns with critical congenital heart disease (CHD) and to study relationships among the neurological abnormalities, CHD type and clinical characteristics in the group. Methods: Term newborns with critical CHD without genetic disorders were retrospectively studied. Neurological abnormalities were grouped according to Amiel-Tison neurological assessment (ATNA). CHD was categorized into five subgroups according to the physiological presentation. Results: In the period observed 190 newborns with critical CHD were admitted. Of 134 who met the inclusion criteria, ATNA was optimal in $64 \%$; in $28.5 \%$ it was mildly, in $6.5 \%$ moderately, and in $1 \%$ severely abnormal. The difference in the frequency of abnormal ATNA between the five CHD subgroups was not statistically significant $(p=0.098)$. A weak association was identified between CHD subgroups and an abnormal ATNA (contingency coefficient 0.246). Newborns with abnormal ATNA had more often $\mathrm{SpO}_{2}<92 \%(\mathrm{p}=0.028)$ and abnormal results of cerebral ultrasound $(p=0.001)$. Conclusion: This study establishes the value of Amiel-Tison standardized neurological examination in assessing the risk of neurodevelopmental disorders among newborns with CHD. We found preoperative neurological abnormalities in one-third of newborns with CHD, and the grade of abnormalities was generally mild or moderate. Newborns with an abnormal ATNA more frequently presented an oxygen saturation $<92 \%$ and abnormal results on the cranial ultrasound.
\end{abstract}

\section{Keywords}

Congenital heart disease, Amiel-Tison neurological assessment, Newborn

\section{Introduction}

Children with congenital heart diseases (CHD) are more likely to have developmental disorders and disabilities compared to their healthy peers [1-3]. According to follow-up studies, the prevalence and severity of neurodevelopmental impairment increases with the complexity of CHD [4, 5]. The knowledge about brain development in fetuses with complex CHD and types of brain abnormalities in children with CHD prior to cardiac surgery has significantly expanded [6]. Researchers have increasingly recognized that alterations in long-term neurodevelopmental outcomes result not only secondary to circulatory consequences of the cardiac abnormality and surgery but also because the brain may primarily develop differently in children with complex CHD [4, 7]. Preoperative abnormalities in the brain structure detected with neuro-radiological examinations may also differ according to the type of CHD [6], but clinical studies of neurological dysfunction before surgery are scarce. Preoperative neurological abnormalities were studied in mixed groups of children with CHD $[2,8]$ and in more homogeneous groups of children with CHD, such as transposition of great arteries (TGA) [9] and hypoplastic left heart syndrome (HLHS) [10]. To date, the grading of preoperative neurological abnormalities using a structured neurological assessment related to the physiological classification of CHD has not been analyzed yet. The Amiel-Tison neurological assessment (ATNA) is based on scoring the most meaningful items with final grading of severity of neurological signs. The sensitivity of the ATNA for detecting ultrasound brain abnormalities and identifying children at risk of developmental disabilities proved to be high [11].

Based on these facts, our study aimed to grade the preoperative neurological abnormalities and analyze the relationships between the preoperative neurological assessments (ATNA), CHD type according to physiological features, clinical characteristics and cranial ultrasonography (CUS) results in a group of newborns with a critical CHD. To the best of our knowledge, this study is the first aiming to grade the neurological abnormalities with standardized neurological examination in neonates with CHD prior to surgery, allowing consistency in assessments between providers, which is clinically relevant to the child's neurologist who often sees these patients prior to 
TA B L E 1. The distribution of different types of congenital heart disease in the cohort.

\begin{tabular}{|c|c|c|c|}
\hline Type of CHD according to the physiological features & Type of defect & No. of patients & $\%$ \\
\hline Obstruction of & CoA Aortic stenosis & 1810 & 20.9 \\
\hline systemic blood flow & Total & 28 & \\
\hline Volume & $\begin{array}{c}\text { TAPVR VSD AVSD TA } \\
\text { Double outlet RV with VSD }\end{array}$ & 230742 & 33.6 \\
\hline overload & Total & 45 & \\
\hline Obstruction of & $\begin{array}{c}\text { TF PS PA Double outlet RV } \\
\text { with PS Ebstein anatomy }\end{array}$ & 1811312 & 26.1 \\
\hline pulmonary blood & Total & 35 & \\
\hline Parallel circulation $=$ TGA & & 21 & 15.7 \\
\hline Single ventricle & HLHV HRHV & 32 & 3.7 \\
\hline physiology & Total & 5 & \\
\hline Total & & 134 & 100 \\
\hline
\end{tabular}

Legend: CHD - congenital heart disease, CoA - coarctation of the aorta, TAPVR - total anomalous pulmonary venous return without obstruction, VSD - ventricular septal defect, AVSD - atrioventricular septal defect, TA - truncus arteriosus, RV - right ventricle, TF - tetralogy of Fallot, PS - pulmonary stenosis, PA - pulmonary atresia, TGA transposition of great arteries, HLHV - hypoplastic left heart ventricle, HRHV-hypoplastic right heart ventricle.

and after surgery for ongoing follow up.

\section{Materials and Methods}

\subsection{Study population}

Newborns with CHD who were admitted to the Department of Neonatology, Division of Paediatrics, University Medical Centre Ljubljana between January 2010 and December 2016 were studied retrospectively. The study was approved by the National Medical Ethics Committee.

Inclusion and exclusion criteria: Infants with critical CHD, up to 28 days of age, with a gestational age $(\mathrm{GA})>36$ weeks were included in the study. We excluded children with genetic malformation syndromes and birth asphyxia (5-minute Apgar score $\leq 5$ ). Additionally, children who required mechanical ventilation and vasoactive support immediately after birth were excluded. A critical CHD was defined as a CHD that required surgery or intervention (like balloon atrial septostomy, balloon dilatation for valve stenosis, etc.) in the first months of life [12].

\subsection{Methods}

$C$ HDs were classified into 5 subgroups according to their physiological features [13]: I) obstruction of systemic blood flow, II) volume overload, III) obstruction of pulmonary blood flow, IV) transposition of great arteries (TGA) V) single ventricle physiology. Data on anthropometric parameters at birth, Apgar scores, $\mathrm{SpO}_{2}$ on admission to the department, prenatal diagnosis of CHD, need for balloon atrial septostomy (BAS) and continuous infusion of prostaglandin E1 (PGE) were collected, as well as the results of ATNA and CUS. The results of ATNA and CUS were reviewed from the documentation without knowledge of the type of CHD.

ATNA was performed during hospitalization by an experienced neonatologist (DPP, JLK, PF, ASS or GN) as part of a standard clinical assessment prior to surgery (if the surgery was performed in the neonatal period) or before discharge (if the surgery was planned later), always in the first 4 weeks of life. It was classified according to Amiel-Tison scale as optimal, mildly (no CNS depression, mild hyperexcitability and tone abnormalities), moderately (drowsiness, poor fixation and tracking, hypoactivity, decreased passive muscle tone in limbs and decreased muscle active tone in neck flexors, decreased or absent neonatal reflexes, and 1 or 2 seizures) or severely abnormal (deep depression of CNS, repeated convulsions lasting for more than 30 minutes) [11]. CUS was performed at the bedside by experienced neonatologists (DPP or ASS ), and the results were classified as normal or abnormal if hypoxic/ischemic, hemorrhagic or structural abnormalities were observed.

\subsection{Statistical analysis}

Data were analyzed using the IBM SPSS Statistics, version 21 (IBM Corporation, Armonk, USA). The differences in the distributions of gender, birth head circumference (HC) and birth weight $(\mathrm{BW})<10$ th percentile for gestational age (GA), prenatal diagnosis of CHD, continuous infusion of PGE, results of CUS (normal, abnormal) and ATNA (normal, abnormal) between the five CHD subgroups were assessed with the $\chi 2$ test, or with the $\chi 2$ goodness-of-fit test for variables where the sample size across the observed categories was too small. Analysis of variance was performed to determine the statistical significance of differences in the mean values for the birth weight and GA between the five CHD subgroups. A nonparametric test for the equality of medians was performed to analyze the statistical significance of differences in $\mathrm{SpO} 2$ upon admission to the department and Apgar scores at 1 and 5 minutes, which are asymmetrically distributed, between the five subgroups. Statistical significance was established at $p$ $<0.05$. Confidence intervals were calculated, taking into 
TA B L E 2. Clinical characteristics of newborns in the five subgroups of congenital heart disease.

$\begin{array}{llcccccc}\text { Subgroup of CHD } & \begin{array}{c}\text { Obstruction } \\ \text { of systemic } \\ \text { blood flow }\end{array} & \begin{array}{c}\text { Volume } \\ \text { overload }\end{array} & \begin{array}{c}\text { Obstruction } \\ \text { of } \\ \text { pulmonary } \\ \text { blood flow }\end{array} & \begin{array}{c}\text { Transposition } \\ \text { of great } \\ \text { arteries }\end{array} & \begin{array}{c}\text { Single } \\ \text { ventricle } \\ \text { physiology }\end{array} & \text { Total } & \text { Statistical test } \\ \text { Male sex No. of pa- } & 19(68 \%) & 23(51 \%) & 23(66 \%)[50 ; & 16(76 \%) & 5(100 \%) & 86(64 \%) & \chi^{2} \mathrm{p}=0.105 \\ \text { tient (\%) [95\% CI] }] & {[47.6 ; 84.1]} & {[36.5 ; 65.7 .1]} & 81.4] & {[52.8 ; 91.8]} & {[100 ; 100]} & {[56.1 ; 72.3]} & \\ \mathrm{N}=134 & & & & & & \end{array}$

\begin{tabular}{|c|c|c|c|c|c|c|c|}
\hline $\begin{array}{l}\begin{array}{l}\text { Gestational } \\
\text { (weeks) }\end{array} \text { age } \\
\text { (SD) }[95 \% \mathrm{CI}] \mathrm{N}= \\
130\end{array}$ & $\begin{array}{c}38.9(1.1) \\
{[38.3 ; 39.4]}\end{array}$ & $\begin{array}{c}38.8(1.6) \\
{[38.3 ; 39.3]}\end{array}$ & $\begin{array}{c}38.9(1.1) \\
{[38.6 ; 39.3]}\end{array}$ & $\begin{array}{c}39.1(1.2) \\
{[38.6 ; 39.7]}\end{array}$ & $\begin{array}{c}39(1.4) \\
{[36.8 ; 41.3]}\end{array}$ & $\begin{array}{c}38.9(1.3) \\
{[38.7 ; 39.1]}\end{array}$ & $F$ test $p=0.894$ \\
\hline $\begin{array}{ll}\text { Birth } & \text { weight (g) } \\
\text { Mean } & (\mathrm{SD}) \quad[95 \%\end{array}$ & $\begin{array}{c}3413(529) \\
{[3209 ; 3617]}\end{array}$ & $\begin{array}{c}3179(525) \\
{[3026 ; 3333]}\end{array}$ & $\begin{array}{c}3255(577) \\
{[3064 ; 3446]}\end{array}$ & $\begin{array}{c}3222(515) \\
{[2988 ; 3456]}\end{array}$ & $\begin{array}{c}3014(776) \\
{[2050 ; 3978]}\end{array}$ & $\begin{array}{c}3248(548) \\
{[3156 ; 3341]}\end{array}$ & $\mathrm{F}$ test $\mathrm{p}=0.381$ \\
\hline
\end{tabular}
CI] $\mathrm{N}=134$

\begin{tabular}{|c|c|c|c|c|c|c|c|}
\hline $\begin{array}{l}\text { Birth weight } \\
<\mathbf{1 0 t h} p \text { for GA, } \\
\text { No. of patients }(\%) \\
{[95 \% \mathrm{CI}] \mathrm{N}=134}\end{array}$ & $\begin{array}{c}3(11)[2.3 ; \\
28.2]\end{array}$ & $\begin{array}{c}9(20)[8.3 ; \\
31.7]\end{array}$ & $\begin{array}{c}8(23)[9.3 \\
37.8]\end{array}$ & $\begin{array}{c}4(19)[5.4 ; \\
41.9]\end{array}$ & $\begin{array}{c}3(60)[14.7 \\
94.7]\end{array}$ & $\begin{array}{c}27(20)[13.4 ; \\
26.9]\end{array}$ & $\begin{array}{c}\chi^{2} \text { goodness-of-fit } \\
\text { test } p=0.250 \text { cont. } \\
\text { coef. }=0.268\end{array}$ \\
\hline $\begin{array}{l}\text { Birth HC }<\mathbf{1 0 t h} p \\
\text { for GA, No. of } \\
\text { patients }(\%) \quad[95 \% \\
\mathrm{CI}] \mathrm{N}=132\end{array}$ & $\begin{array}{c}1(4)[2.3 ; \\
28.2]\end{array}$ & $\begin{array}{c}9(21)[9 ; \\
33.8]\end{array}$ & $\begin{array}{c}8(23)[9.3 ; \\
37.8]\end{array}$ & $\begin{array}{c}2(10)[1.2 ; \\
31.7]\end{array}$ & $\begin{array}{c}1(20)[0.5 \\
71.6]\end{array}$ & $\begin{array}{c}21(16)[9.7 \\
22.1]\end{array}$ & $\begin{array}{l}\chi^{2} \text { goodness-of-fit } \\
\text { test } p=0.299 \text { cont. } \\
\text { coef. }=0.203\end{array}$ \\
\hline
\end{tabular}

1 min Apgar score $8.5(1.2)$ [8.0; $8.5(1.4)$ [8.0; $8.7(0.9)$ [8.4; $8.4(2.0)$ [7.5; $8.6(0.5)$ [7.9; 8.5 (1.3) [8.3; nonparametric test

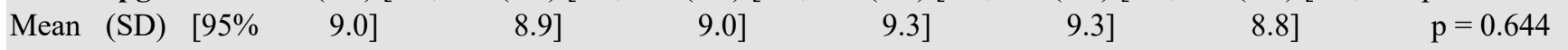
CI] $\mathrm{N}=130$

5 min Apgar score $9.1(0.6)$ [8.9; $9.2(0.6)$ [9.0; $9.2(0.6)$ [9.0; $8.6(2.1)$ [7.6; $8.8(0.4)$ [8.2; 9.1 (1.0) [8.9; nonparametric test

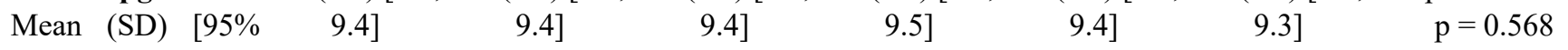
CI] $\mathrm{N}=130$

Prenatal diagnosis $6(23)\left[9.0 ; \quad 5(12)\left[2.2 ; \quad 4(12)[1 ; 24] \quad 6(32)\left[12.6 ; \quad 2(40)\left[5.3 ; 23(18)\left[11.4 ; \chi^{2}\right.\right.\right.\right.\right.$ goodness-of-fit

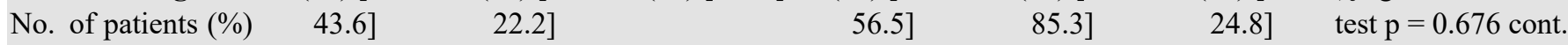
$[95 \% \mathrm{CI}] \mathrm{N}=127 \quad$ coef. $=0.221$

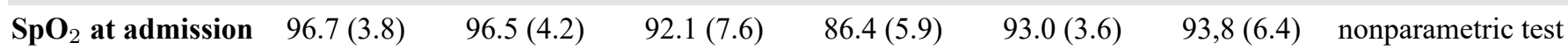
$\begin{array}{lllllllll}\text { in } \% & \text { Mean }(\mathrm{SD}) & {[95.1 ; 98.3]} & {[95.2 ; 97.7]} & {[89.5 ; 94.7]} & {[83.4 ; 89.4]} & {[87.3 ; 98.7]} & {[92.7 ; 95.0]} & p<0.005\end{array}$ $[95 \% \mathrm{CI}] \mathrm{N}=134$

\begin{tabular}{|c|c|c|c|c|c|c|}
\hline $\begin{array}{l}\text { Continuous } \\
\text { infusion of PGE } \\
\text { No. of patients (\%) } \\
{[95 \% \mathrm{CI}] \mathrm{N}=134}\end{array}$ & $\begin{array}{c}18(64)[44.1 ; \\
81.4]\end{array}$ & $0(0)$ & $\begin{array}{l}11(31)[16 \\
46.8]\end{array}$ & $\begin{array}{l}13(62)[38.4 ; \\
\quad 81.9]\end{array}$ & $\begin{array}{l}5(100)[100 ; \\
100]\end{array}$ & $\begin{array}{cc}47(35)[27 ; & \chi^{2} \mathrm{p}<0.005 \text { cont. } \\
43.2] & \text { coef. }=0.525\end{array}$ \\
\hline $\begin{array}{l}\text { Abnormal CUS } \\
\text { No. of patients }(\%) \\
{[95 \% \mathrm{CI}] \mathrm{N}=110}\end{array}$ & $\begin{array}{c}7(32) \text { [13.9; } \\
54.9]\end{array}$ & $\begin{array}{l}14(41)[24.6 \\
57.7]\end{array}$ & $\begin{array}{l}16(52)[34 ; \\
\quad 69.2]\end{array}$ & $\begin{array}{l}10(53)[28.9 ; \\
75.5]\end{array}$ & $3(75)$ & $\begin{array}{cc}50(42)[32.8 ; & \chi^{2} \mathrm{p}=0.382 \text { cont. } \\
50.5] & \text { coef. }=0.191\end{array}$ \\
\hline $\begin{array}{l}\text { Abnormal ATNA } \\
\text { No. of patients (\%) } \\
{[95 \% \mathrm{CI}] \mathrm{N}=122}\end{array}$ & $\begin{array}{l}6(24)[9.4 \\
\quad 45.1]\end{array}$ & $\begin{array}{l}15(35)[20.6 \\
49.1]\end{array}$ & $\begin{array}{c}13(39)[22.7 ; \\
56.1]\end{array}$ & $\begin{array}{l}10(59)[32.9 ; \\
81.6]\end{array}$ & $0(0)$ & $\begin{array}{cc}44(36) & \chi^{2} p=0.098 \text { cont. } \\
{[13.4 ; 26.9]} & \text { coef. }=0.246\end{array}$ \\
\hline
\end{tabular}

Legend: $G A=$ gestational age, $H C=$ head circumference, $S p O 2=$ oxygen saturation, $P G E=$ prostaglandin E1, $C U S=$ cranial ultrasound, ATNA = Amiel-Tison neurological assessment, $S D=$ standard deviation, $C I=$ confidence interval.

account the sample size (for means, the $\mathrm{Z}$ distribution for large samples and $t$ distribution for small samples, and, for percentages, the $\mathrm{Z}$ distribution for large samples and ClopperPearson confidence interval for small samples).

Additionally, we determined the proportions of abnormal
ATNA results among children who differed in the requirement for a continuous PGE infusion (in this analysis we excluded children from the 2nd CHD subgroup with volume overload, since they do not require a PGE infusion), $\mathrm{SpO} 2<92 \%$ on admission to the department, birth $\mathrm{HC}<10$ th percentile for 
TA B L E 3. Results of the cerebral ultrasound.

\begin{tabular}{lc} 
Cerebral ultrasound & No. of patients $(\mathbf{N}=\mathbf{5 0 *})$ \\
Lenticulostriate vasculopathy & 25 \\
Periventricular hyperechogenicity & 16 \\
Bigger cisterna magna & 8 \\
Hyper echogenicity in basal ganglia & 5 \\
Subependymal hemorrhage & 4 \\
Widened ventricular system & 4 \\
Arterial infarction & 1 \\
Hypoplasia of vermis & 1 \\
Agenesis/hypoplasia of the corpus callosum & 2 \\
\hline *Twelve patients had more than one abnormality (8 had two and 4 had three \\
abnormalities).
\end{tabular}

GA, BW $<10$ th percentile for GA and CUS results. Furthermore, the proportion of abnormal ATNA results observed in children with TGA was determined according to the performed BAS. The $\chi 2$ - test, with the $\chi 2$ goodness-of-fit test in cases of variables where sample size across the observed categories was too small, was performed for each pair of variables.

\section{Results}

In the period observed, 497 newborns with CHD who did not require ventilator support were admitted. One hundred ninety of these patients were diagnosed with a critical CHD. After the exclusion of 56 children with genetic malformation syndrome $(\mathrm{n}=42)$, prematurity $(\mathrm{n}=12)$ and insufficient documentation $(n=2), 134$ newborns were enrolled for further analysis. The distributions of different types of CHD are shown in Table 1.

Clinical characteristics of newborns grouped into the $5 \mathrm{CHD}$ subgroups according to physiological features are presented in Table 2. Compared with the whole group, TGA and single ventricle physiology were more frequently diagnosed prenatally $(32 \%$ and $40 \%)$, but the difference in the distribution was not statistically significant $(\mathrm{p}=0.676)$. Forty-seven newborns $(35 \%, 95 \%$ CI: $27 ; 43.2)$ were treated with a continuous infusion of PGE, the difference in the proportions of newborns requiring a continuous PGE infusion between the five CHD subgroups was statistically significant $(\mathrm{p}<0.005)$. Children with TGA had the lowest $\mathrm{SpO}_{2}$ upon admission to the department (mean $\mathrm{SpO}_{2} 86 \%$ (SD 6)) and the difference in $\mathrm{SpO}_{2}$ between the groups was statistically significant $(\mathrm{p}<0.005)$. Thirteen $(62 \%, 95 \%$ CI: $41.1 ; 82.7)$ children with TGA had BAS.

CUS was performed in 110 (82\%) of newborns with CHD before surgery. It was abnormal in 50 (46\%, $95 \%$ CI: 32.8 ; $50.5)$ patients, but the difference in the frequency of abnormal CUS between the five CHD subgroups was not statistically significant $(p=0.382)$. The types of ultrasound abnormalities detected in the studied cohort are presented in Table 3.

The results of ATNA before surgery were recorded in 122 (91\%) newborns. In 78 newborns (64\%, 95\% CI: 55.4; 72.5), the ATNA was normal, but mild, moderate, and severe abnormalities were observed in $35(29 \%, 95 \%$ CI: $20.7 ; 36.7), 8(7 \%$,
95\% CI: $2.7 ; 12.0)$ and one $(1 \%, 95 \%$ CI: $0 ; 2.4)$ newborn, respectively. Newborns with TGA more frequently presented an abnormal ATNA, but the difference in the frequency of abnormal ATNA between the five CHD subgroups was not statistically significant $(\mathrm{p}=0.098)$. A weak association was identified between CHD subgroups and an abnormal ATNA (contingency coefficient 0.246 ). The distribution of the grades of severity of neurological signs in the five CHD subgroups is presented in Fig. 1.

Children with an abnormal ATNA more frequently had an abnormal CUS $(p=0.001)$, and the frequency of abnormal CUS results in children with different grades of abnormal ATNA is shown in Fig. 2. Newborns with $\mathrm{SpO}_{2}<92 \%$ upon admission to the department more frequently had an abnormal ATNA than newborns with $\mathrm{SpO}_{2} \geq 92 \%$ (53\% vs $28 \%, p=0.028$. No associations were observed among BAS performance, continuous PGE infusion, small HC, small BW and abnormal ATNA (Table 4).

\section{Discussion}

Since the first reports on clinical neurological abnormalities in newborns with CHD before surgery were published, multiple studies on brain magnetic resonance imaging (MRI) have significantly expanded our knowledge of the preoperative brain injuries observed in this group of children. Due to a high incidence of neurodevelopmental disabilities in children with CHD, a structural neurological approach in clinical settings is needed for the early recognition of children who require further diagnostic measures and treatment and to improve longitudinal neurodevelopmental surveillance [14]. In the present study, we therefore graded neurological signs using the Amiel-Tison method and studied the relations to the type of CHD, clinical data and CUS results.

In our heterogeneous cohort of newborns with CHD, abnormal neurological findings were present in $36 \%(95 \% \mathrm{CI}$ : 27.5 ; 44.6) of children and were predominantly of a mild grade (no CNS depression, mild hyperexcitability and tone abnormalities). Our results are therefore consistent with the previously reported prevalence $(25-56 \%)$ of preoperative neurodevelopmental abnormalities in heterogeneous groups of 


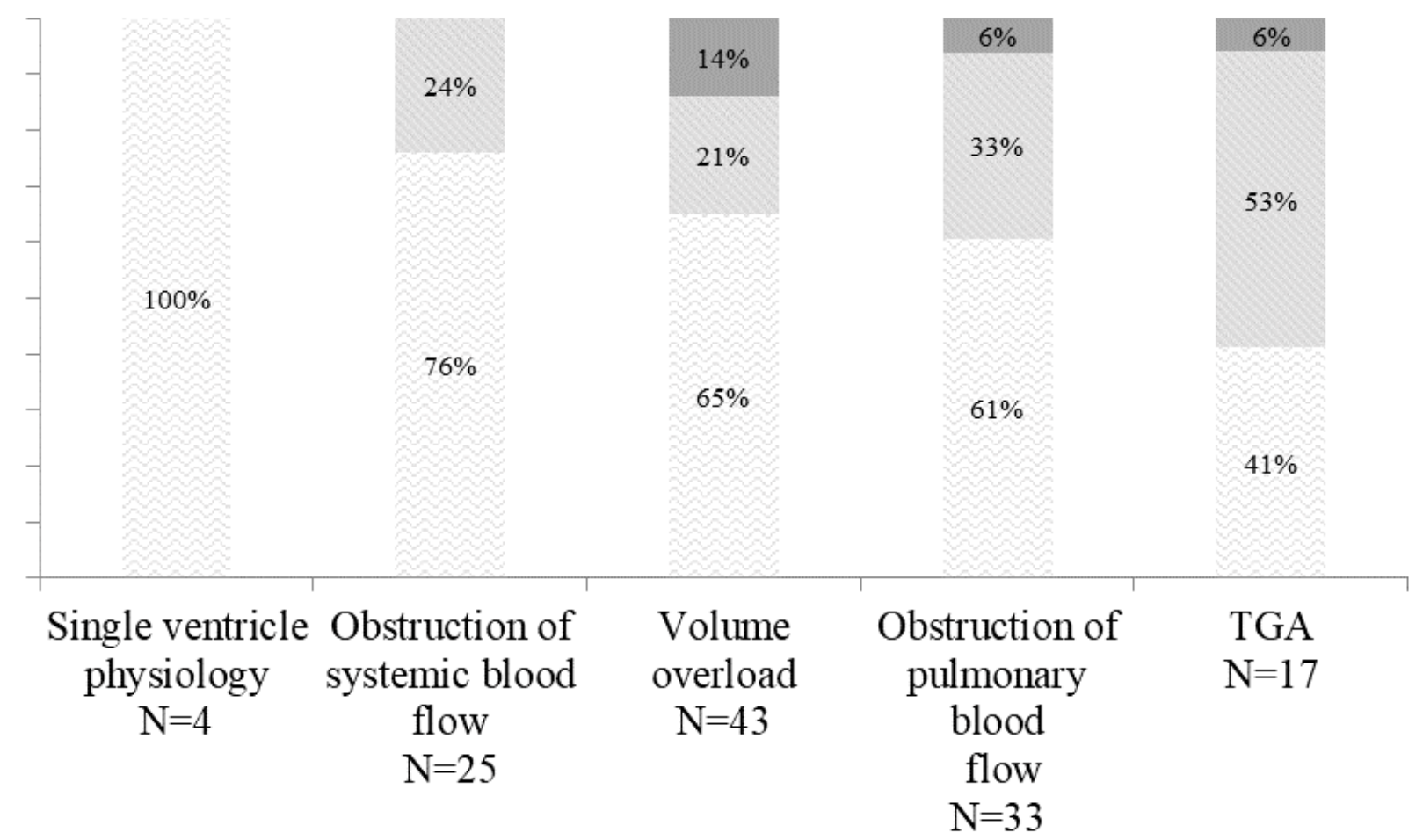

\section{ATNA Optimal Mildly abnormal Moderately/severely abnormal}

F I G U RE 1. Results of the Amiel-Tison neurological assessment in patients stratified according to five subgroups of congenital heart disease.

Legend: ATNA = Amiel-Tison neurological assessment, TGA $=$ transposition of great arteries .

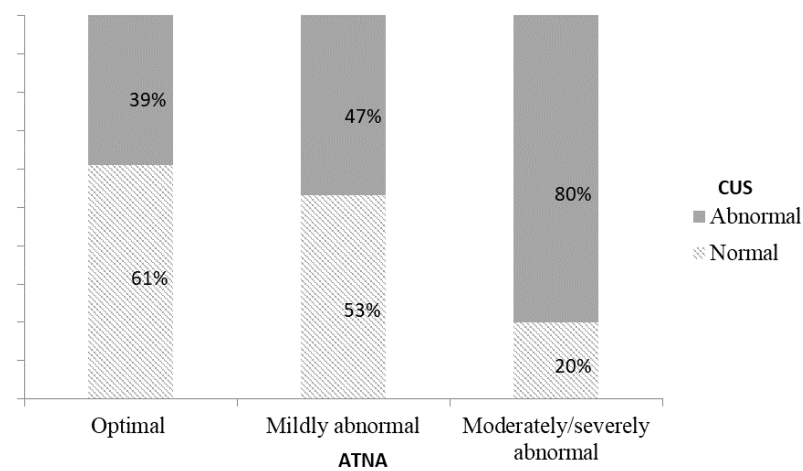

F IGURE 2. Results of the cranial ultrasound for patients stratified according to Amiel-Tison neurological assessment.

Legend: ATNA = Amiel-Tison neurological assessment, CUS = cranial ultrasound.

newborns with CHD, although the authors did not grade the abnormalities [6]. Some of the first studies addressing neurobehavioral and neurological abnormalities in heterogeneous groups of newborns with CHD before surgery was conducted by Limperopoulos et al. [2, 15]. In their cohort, neurobehavioral and neurological abnormalities were documented in more than half of the newborns. Similar findings were observed by Majnemer et al., who reported preoperative abnormalities in $46 \%$ of children in the heterogeneous group with a CHD [8].
The prevalence of developmental disorders or disabilities and developmental delay in children and young adults with CHD increases with the complexity of CHD [16-18], such as TGA and HLHS. In our cohort, the differences in the proportions of newborns with an abnormal ATNA between the five CHD subgroups were not statistically significant, although the group with TGA exhibited the highest frequency of abnormal ATNA (58\%) and the association between CHD subgroups and abnormal ATNA was weak. A high prevalence of neurological abnormalities among newborns with TGA (70\%) was also reported by Miller et al. [9]. Children with 'single ventricle physiology' in our cohort had a normal ATNA before surgery, but the number of newborns in this subgroup of patients with CHD was too small to draw any general conclusions. Interestingly, $35 \%$ of newborns with 'volume overflow' CHD, which is often considered to result in a low risk of neurologic abnormalities, had an abnormal ATNA (95\% CI: 20.6; 49.1). The relatively high prevalence of abnormal ATNA in this group is probably due to the study inclusion criteria, which resulted in the inclusion of patients with hemodynamically important 'volume overload' CHD requiring surgery, a condition that is often present with heart failure in first month and is associated with alterations in cerebral blood flow [19, 20].

We analyzed the relations between ATNA and some clinical data and found that newborns presenting with $\mathrm{SpO} 2<92 \%$ upon admission to the department more frequently had an abnormal ATNA compared to children who had $\mathrm{SpO} 2 \geq 92 \%$ 
T A B L E 4. Amiel-Tison neurological assessment of the SpO2, results of the cerebral ultrasound, balloon atrial septostomy, infusion of prostaglandin and measures at birth.

\begin{tabular}{|c|c|c|c|c|c|c|}
\hline & & ATNA & & & & Statistical test \\
\hline & & Normal n (\%) & $\begin{array}{c}\text { Mildly } \\
\text { abnormal n (\%) }\end{array}$ & $\begin{array}{c}\text { Moderately/ } \\
\text { severely } \\
\text { abnormal n (\%) }\end{array}$ & Total n & \\
\hline & & $78(64)$ & $35(29)$ & $9(7)$ & 122 & \\
\hline \multirow[t]{2}{*}{$\begin{array}{l}\text { SpO_2 at admission N } \\
=112\end{array}$} & $<92 \%$ & $17(47)$ & $16(44)$ & $3(8)$ & 36 & $\begin{array}{l}\chi^{2} p=0.028 \text { cont. } \\
\text { coef. }=0.246\end{array}$ \\
\hline & $>92 \%$ & $55(72)$ & $16(21)$ & $5(7)$ & 76 & \\
\hline \multirow[t]{2}{*}{$\begin{array}{l}\text { Head circumference at } \\
\text { birth } N=120\end{array}$} & $<10^{t h} \mathrm{p}$ & $12(60)$ & $6(30)$ & $2(10)$ & 20 & $\begin{array}{l}\chi^{2} p=0.866 \text { cont. } \\
\text { coef. }=0.049\end{array}$ \\
\hline & $>10^{t h} \mathrm{p}$ & $65(65)$ & $28(28)$ & $7(7)$ & 100 & \\
\hline \multirow[t]{2}{*}{ Birth weight $\mathrm{N}=122$} & $<10^{t h} \mathrm{p}$ & $20(77)$ & $4(15)$ & $2(8)$ & 26 & $\begin{array}{c}\chi^{2} p=0.233 \text { cont. } \\
\text { coef. }=0.153\end{array}$ \\
\hline & $>10^{t h} \mathrm{p}$ & $58(60)$ & $31(32)$ & $7(7)$ & 96 & \\
\hline \multirow[t]{2}{*}{ CUS N $=101$} & Normal & $39(68)$ & $17(30)$ & $1(2)$ & 57 & $\begin{array}{c}\chi^{2} \text { goodness-of-fit } \\
\text { test } p=0.001\end{array}$ \\
\hline & Abnormal & $25(57)$ & $15(34)$ & $4(9)$ & 44 & \\
\hline \multirow[t]{2}{*}{$\begin{array}{l}\text { BAS for newborns with } \\
\text { TGA } N=17\end{array}$} & Yes & $4(40)$ & $5(50)$ & $1(10)$ & 10 & $\begin{array}{c}\chi^{2} \text { goodness-of-fit } \\
\text { test } p=0.675\end{array}$ \\
\hline & No & $3(43)$ & $4(57)$ & $0(0)$ & 7 & \\
\hline \multirow[t]{2}{*}{$\begin{array}{l}\text { Continuous PGE infu- } \\
\text { sion * } N=79\end{array}$} & Yes & $25(63)$ & $13(33)$ & $2(5)$ & 40 & $\begin{array}{c}\chi^{2} \text { goodness-of-fit } \\
\text { test } p=0.635\end{array}$ \\
\hline & No & $25(64)$ & $13(33)$ & $1(3)$ & 39 & \\
\hline
\end{tabular}

Legend: $A T N A=$ Amiel-Tison neurological assessment, $\mathrm{Sp} \mathrm{O}_{2}=$ oxygen saturation, $\mathrm{CUS}=$ cranial ultrasound, $\mathrm{BAS}$ = balloon atrial septostomy, TGA - transposition of great arteries, PGE = prostaglandin E1. * In the analysis, we excluded children from the $2^{\text {nd }}$ CHD subgroup.

$(p=0.028)$. The association between oxygen saturation and a negative neurodevelopmental outcome has already been outlined in some other studies [2, 21-23] and may explain the high prevalence of abnormal ATNA in children with TGA. These findings are consistent with studies supporting the hypothesis that the macro and microstructural changes of cerebral cortex observed in children with CHD result from altered cerebral oxygen delivery [24, 25].

Despite the established mechanisms that preserve blood delivery to the brain in the fetus, newborns with CHD are often born with a smaller HC [26]. Several studies identified microcephaly as a risk factor for persistent developmental deficits $[4,27,28]$. In the study by Limpelopulus et al., $67 \%$ of newborns with microcephaly had abnormal neurological findings, but the association between microcephaly and an abnormal neurological status was not statistically significant [15]. The correlation between preoperative brain injury detected using MRI and clinical variables was addressed by Beca et al., and a small HC was not associated with brain injury [29]. However, the American Heart Association has acknowledged a small $\mathrm{HC}$ as one of the few well-established risk factors for impaired neurodevelopment in children with CHD [4]. Abnormalities in a cranial assessment determined by measuring the $\mathrm{HC}$ and palpating squamous and other sutures are already one of the criteria for nonoptimality in the ATNA and were present in $16 \%(95 \%$ CI: $9.7 ; 22.1)$ of children in our cohort.

The systematic review of brain abnormalities assessed using MRI or CUS in infants with CHD before surgery revealed the pooled prevalence of brain lesions of $34 \%$ in infants with TGA, $49 \%$ in infants with left side heart lesions and $46 \%$ in infants with mixed/unspecified lesions [6]. The brain abnormalities observed using CUS included a widened ventricular or subarachnoid space, cerebral atrophy, intraventricular hemorrhage, thalamostriate vasculopathy, parenchyma hyperechogenicity, periventricular leukomalacia and edema [3032]. In our study, $45 \%$ (95\% CI: $36.1,54.8)$ of newborns presented abnormal CUS results, similar to the proportion (42\%) reported by Te Pas and colleagues [30], but the difference in the prevalence of abnormal CUS results between the five CHD subgroups was not statistically significant. Te Pas et al. reported widened ventricles and/or subarachnoid space as the most common findings, while in our study, lenticulostriate vasculopathy and periventricular hyperechogenicity were the most frequently observed changes [30].

In the present study, infants with an abnormal ATNA were more likely to present an abnormal CUS and the difference was statistically significant $(\mathrm{p}=0.001)$. A systematic review addressing the association between preoperative findings and neurodevelopmental outcomes in infants with CHD suggests 
that abnormal cerebral findings before surgery might be associated with poorer neurodevelopmental outcomes later in life [33]. Additionally, the American Heart Association recognizes neuroimaging abnormalities as a risk factor for impaired neurodevelopment, categorizing CHD patients with neuroimaging abnormalities into the high-risk group for developmental disorders or disabilities [4].

PGE is widely administered to patients with ductusdependent CHD prior to the operation to improve oxygenation and possibly cerebral blood flow, both of which potentially influence the neurodevelopmental outcome. In addition, an imbalance between systemic and pulmonary perfusion may occur during PGE treatment, also influencing cerebral perfusion [34]. In our cohort, we did not identify any association between a continuous PGE infusion and ATNA results, similar to McQuillen et al., who did not observe an association between PGE treatment and preoperative brain injury [35].

We would like to emphasize that our study cohort is particularly special due to the exclusion of preterm newborns and newborns with a genetic disease or severe circulatory compromise after delivery and before surgery. Using this approach, we were able to study the effect of prenatal CHDinduced hemodynamic changes on the neurological function. MRI and Doppler echocardiography studies have already detected abnormalities of fetal blood flow and reduced substrate delivery, leading to an immaturity of the developing brain [36]. In the absence of congenital structural CNS abnormalities, stroke and hemorrhage in fetuses and newborns with CHD, which has also been described, the prenatal circulatory changes represent a potential etiological factor for some neurological abnormalities resulting in "Congenital Brain Disease" [36].

Our study has several limitations. We retrospectively studied a heterogeneous population of newborns with CHD, and the number of infants in the CHD subgroups was low. We postulate that the lack of statistical significance in differences in ATNA results between CHD subgroups may be related to the relatively small number of patients in each group. In addition, our study employed a retrospective design, and thus some clinical data were unable to be adequately addressed. Moreover, due to the retrospective data retrieval process, some data were missing and the results may not be completely accurate. Furthermore, physicians performing ATNA and CUS were not blinded to the newborns' medical conditions; nevertheless, they were not aware of the future study, which is likely to reduce at least some of the assessment bias. We excluded newborns with hemodynamic and respiratory instability after the birth who required invasive respiratory support, and therefore the prevalence of neurological abnormalities does not apply to the whole population of newborns with a critical CHD. In the future, we intend to analyze the relation between preoperative results of ATNA and long-term neurodevelopmental outcomes in our group.

\section{Conclusions}

We found preoperative neurological abnormalities in one-third of newborns with CHD, and the grade of abnormalities was generally mild or moderate. Although newborns with TGA had the highest prevalence of neurological abnormalities, we did not observe an association between the ATNA results and five CHD subgroups. An abnormal ATNA was more frequently present in newborns with $\mathrm{SpO}_{2}<92 \%$, supporting the hypothesis that reduced cerebral oxygen delivery in infants with CHD without a genetic disorder is a cause of impaired brain development that probably results in neurological dysfunction. Further studies are needed in the future to assess whether the abnormal neurological assessment before surgery is associated with abnormal neurodevelopmental outcomes later in life. The identification of infants with CHD who are at risk of neurodevelopmental impairments before surgery may guide the clinical management and early intervention in this vulnerable group of children.

\section{ACKNOWLEDGMENTS}

The authors thank Katja Lozar Manfreda for providing assistance with the statistical analysis. We are grateful to Petja Fister, Gregor Nosan and Aneta Soltirovska Šalamon who performed the ATNA and CUS.

\section{CONFLICT OF INTEREST}

All authors declare that they have no conflict of interest.

\section{FUNDING STATEMENT}

No benefits in any form have been received or will be received from a commercial party related directly or indirectly to the subject of this article.

\section{ETHICAL STATEMENT}

Ethical approval: All procedures performed were in accordance with the ethical standards of the institutional and/or national research committee and with the 1964 Helsinki declaration and its later amendments or comparable ethical standards.

\section{REFERENCES}

[1] Ferry PC. Neurologic sequelae of open-heart surgery in children. An 'irritating question'. Am J Dis Child. 1990;144:369-373.

[2] Limperopoulos C, Majnemer A, Shevell MI, et al. Neurodevelopmental status of newborns and infants with congenital heart defects before and after open heart surgery. J Pediatr. 2000;137:638-645.

[3] Mahle WT. Neurologic and cognitive outcomes in children with congenital heart disease. Curr Opin Pediatr. 2001;13:482-486.

[4] Marino BS, Lipkin PH, Newburger JW, et al. American Heart Association Congenital Heart Defects Committee, Council on Cardiovascular Disease in the Young, Council on Cardiovascular Nursing, and Stroke Council. Neurodevelopmental outcomes in children with congenital heart disease: evaluation and management: a scientific statement from the American Heart Association. Circulation. 2012;126:1143-1172.

[5] Latal B. Neurodevelopmental Outcomes of the Child with Congenital Heart Disease. Clin Perinatol. 2016;43:173-185.

[6] Khalil A, Suff N, Thilaganathan B, et al. Brain abnormalities and neurodevelopmental delay in congenital heart disease: systematic review and meta-analysis. Ultrasound Obstet Gynecol. 2014;43:14-24.

[7] Massaro AN, El-Dib M, Glass P, et al. Factors associated with adverse 
neurodevelopmental outcomes in infants with congenital heart disease. Brain Dev. 2008;30:437-446.

[8] Majnemer A, Limperopoulos C, Shevell MI, et al. A new look at outcomes of infants with congenital heart disease. Pediatr Neurol. 2009;40:197-204.

[9] Miller SP, McQuillen PS, Vigneron DB, et al. Preoperative brain injury in newborns with transposition of the great arteries. Ann Thorac Surg. 2004;77:1698-706.

[10] Dent CL, Spaeth JP, Jones BV, et al. Brain magnetic resonance imaging abnormalities after the Norwood procedure using regional cerebral perfusion. J Thorac Cardiovasc Surg. 2006;131:190-197.

[11] Paro-Panjan D, Neubauer D, Kodric J, et al. Amiel-Tison Neurological Assessment at term age: clinical application, correlation with other methods, and outcome at 12 to 15 months. Dev Med Child Neurol. 2005;47:19-26.

[12] Olney RS, Ailes EC, Sontag MK. Detection of critical congenital heart defects: Review of contributions from prenatal and newborn screening. Semin Perinatol. 2015;39:230-237.

[13] Berger JT, Schwartz SM, Nelson DP. Congenital heart disease. In: Slonim AD, Pollack MM. Pediatric Critical Care Medicine. Philadelphia: Lippincott Williams \& Wilkins \& Wolters Kluwer business; 2006.p. 623632 .

[14] Glotzbach KL, Ward JJ, Marietta J, et al. The Benefits and Bias in Neurodevelopmental Evaluation for Children with Congenital Heart Disease. Pediatr Cardiol. 2020;41:327-333.

[15] Limperopoulos C, Majnemer A, Shevell MI, et al. Neurologic status of newborns with congenital heart defects before open heart surgery. Pediatrics. 1999;103:402-408.

[16] Mahle WT, Wernovsky G. Long-term developmental outcome of children with complex congenital heart disease. Clin Perinatol. 2001;28:235-247.

[17] Wernovsky G. Current insights regarding neurological and developmental abnormalities in children and young adults with complex congenital cardiac disease. Cardiol Young. 2006;16:92-104.

[18] Martinez-Biarge M, Jowett VC, Cowan FM, et al. Neurodevelopmental outcome in children with congenital heart disease. Semin Fetal Neonatal Med. 2013;18:279-285

[19] Kojo M, Yamada K, Akiyoshi S, et al. Reduction of carotid arterial blood flow in ventricular septal defect associated with severe congestive heart failure. J Neuroimaging. 2000;10:241-243.

[20] Ozturk Tasar N, Kosger P, Uzuner N, et al. Alterations in cerebral blood flow in children with congestive heart failure due to ventricular septal defect. Congenit Heart Dis. 2018;13:1038-1044.

[21] Chock VY, Reddy VM, Bernstein D, et al. Neurologic events in neonates treated surgically for congenital heart disease. J Perinatol. 2006;26:237242 .

[22] Gessler P, Schmitt B, Pr'etre R, et al. Inflammatory response and neurodevelopmental outcome after open-heart surgery in children. Pediatr Cardiol. 2009;30:301-305.

[23] Petit CJ, Rome JJ, Wernovsky G, et al. Preoperative brain injury in transposition of the great arteries is associated with oxygenation and time to surgery, not balloon atrial septostomy. Circulation. 2009;119:709-716.

[24] Kelly CJ, Makropoulos A, Cordero-Grande L, et al. Impaired development of the cerebral cortex in infants with congenital heart disease is correlated to reduced cerebral oxygen delivery. Sci Rep. 2017;7:15088.

[25] Kelly CJ, Christiaens D, Batalle D, et al. Abnormal Microstructural Development of the Cerebral Cortex in Neonates With Congenital Heart Disease Is Associated With Impaired Cerebral Oxygen Delivery. J Am Heart Assoc. 2019; 8:e009893.

[26] Rosenthal GL. Patterns of prenatal growth among infants with cardiovascular malformations: possible fetal hemodynamic effects. Am J Epidemiol. 1996;143:505-513.

[27] Limperopoulos C, Majnemer A, Shevell MI, et al. Predictors of developmental disabilities after open heart surgery in young children with congenital heart defects. J Pediatr. 2006;141:51-58.

[28] Majnemer A, Limperopoulos C, Shevell M,et al. Long-term neuromotor outcome at school entry of infants with congenital heart defects requiring open-heart surgery. J Pediatr. 2006;148:72-77.

[29] Beca J, Gunn J, Coleman L, et al. Pre-operative brain injury in newborn infants with transposition of the great arteries occurs at rates similar to other complex congenital heart disease and is not related to balloon atrial septostomy. J Am Coll Cardiol. 2009;53:1807-1811.

[30] Te Pas A, Van Wezel-Meijler G, Bokenkamp-Gramann R, et al. Preoperative cranial ultrasound findings in infants with major congenital heart disease. Acta Paediatr. 2005;94:1597-1603.

[31] van Houten J, Rothman A, Bejar R. High incidence of cranial ultrasound abnormalities in full-term infants with congenital heart disease. Am J Perinatol. 1996;13:47-53.

[32] Latal B, Kellenberger C, Dimitropoulos A, et al. Can preoperative cranial ultrasound predict early neurodevelopmental outcome in infants with congenital heart disease? Dev Med Child Neurol. 2015;54:639-644.

[33] Mebius MJ, Kooi EMW, Bilardo CM, et al. Brain Injury and Neurodevelopmental Outcome in Congenital Heart Disease: A Systematic Review. Pediatrics. 2017;140:e20164055.

[34] Heymann MA, Clyman RI. Evaluation of alprostadil (prostaglandin E1) in the management of congenital heart disease in infancy. Pharmacotherapy. 1982;2:148-155.

[35] McQuillen PS, Hamrick SE, Perez MJ, et al. Balloon atrial septostomy is associated with preoperative stroke in neonates with transposition of the great arteries. Circulation. 2006;113:280-285.

[36] Wernovsky G, Licht DJ. Neurodevelopmental Outcomes in Children With Congenital Heart Disease-What Can We Impact? Pediatr Crit Care Med. 2016;17:S232-242.

How to cite this article: Lozar Krivec J, Kosmač B, Paro-Panjan D. Preoperative Clinical Neurological Assessment in New-borns with Critical Congenital Heart Disease. Signa Vitae. 2020;16(2):29-36. doi: $10.22514 /$ sv.2020.16.0067. 